\title{
Stomach Cancer - Prevention with a Plant-Based Diet
}

\author{
Stewart Rose and Amanda Strombom* \\ Plant-Based Diets in Medicine, USA
}

Submission: July 20, 2021; Published: July 27, 2021

*Corresponding author: Amanda Strombom, Plant-Based Diets in Medicine, 12819 SE 38th St, \#427, Bellevue, WA 98006, USA

\section{Abstract}

Worldwide, stomach or gastric cancer is the third leading cause of cancer death. Unfortunately, diagnosis often occurs at a late stage, and standard treatment involving radical surgery results in more than half of patients relapsing locally or with distant metastases. Median survival rarely exceeds 12 months, and in metastatic setting, 5 -year survival is less than $10 \%$. Given that standard treatment is not very efficacious, the emphasis needs to be on prevention. Dietary factors have an important impact on gastric carcinogenesis, especially in case of the intestinal type of gastric adenocarcinoma. Healthy dietary habits, that is, high intake of fresh fruits and vegetables, a Mediterranean diet, a low-sodium diet, avoiding salt-preserved food, red and high cured meat, sensible alcohol drinking, and maintaining a proper weight are all associated with a decreased risk of gastric cancer. There is consistent evidence that Helicobacter pylori (H. pylori) infection of the stomach is strongly associated with both the initiation and promotion of carcinoma of the gastric body and antrum and of gastric lymphoma. It is believed that dietary factors may contribute to the H. pylori infection by providing noxious agents that contribute to H. pylori pathogenicity. Adequate nutritional status, especially high consumption of fruits, vegetables, and vitamin C, appears to protect against the pathological consequences of H. pylori infection.

Patient compliance on plant-based diets has been good in almost all studies. Compliance may be enhanced when the rationale for the treatment, and that the treatment is backed by research, is explained to the patient.

\section{Introduction}

Worldwide, stomach or gastric cancer is the third leading cause of cancer death, with the highest rates reported in East Asia, South America and Eastern Europe [1]. The overall 5-year relative survival rate for stomach cancer, which was $14.3 \%$ in 1975, rose to $32.0 \%$ by $2010-2016$. During that period, the 5 -year relative survival rate by stage at diagnosis was $69.5 \%$ for localized disease, $32.0 \%$ for regional disease, and $5.5 \%$ for distant disease [2].

There are several types of cancers arising from the stomach. The majority (about 90\%) of stomach cancers belong to the group of adenocarcinomas, which originate from the glands of the gastric mucosa [3]. They are the focus of this article. Besides adenocarcinomas, other types of cancers may arise from lymphoid tissue and muscles of the stomach. For example, mucosa-associated lymphoid tissue lymphomas are derived from gastric lymphoid tissues, and leiomyosarcomas originate from the muscles below the mucosa [3], but they will not be considered in this article.

Gastric ulcer disease and gastric cancer have etiologic factors in common. A likely cause of both is atrophic gastritis induced by Helicobacter pylori (H. pylori) [4]. While H. pylori is commonly implicated in the pathogenesis of benign ulceration [5], the risk of malignant change in gastric ulcer has long been recognized [6]. In the literature, the rate of malignancy in endoscopically diagnosed gastric ulcers varies considerably, ranging from $2.4 \%-21 \%[7,8]$. Both gastric and duodenal ulcers are more associated with noncardia gastric cancer than with cardia cancer [9].

Early symptoms of gastric cancer resemble those of chronic gastritis, including dyspepsia, dysphagia, and nausea. As a result, the cancer is often diagnosed at advanced stages when clinical manifestations such as weight loss, anorexia, altered bowel habits, anemia, and hemorrhage trigger diagnostic evaluation [10]. Radical surgery represents the standard form of therapy that has curative intent. However, the incidences of local failure in the tumor bed and regional lymph nodes, and distant failures via hematogenous or peritoneal routes, remain high [11]. As such, comprehensive staging and evaluation with a multidisciplinary team to determine roles of neoadjuvant, perioperative, and adjuvant combination chemotherapy, surgery, and external-beam radiation therapies is current standard of care [11]. Unfortunately, more than half of radically resected gastric cancer patients relapse locally or with distant metastases or receive the diagnosis 


\section{Cancer Therapy \& Oncology International Journal}

of gastric cancer when the tumor is disseminated; therefore, median survival rarely exceeds 12 months, and in metastatic setting, 5-year survival is less than 10\% [12]. Given that standard treatment is not very efficacious, the emphasis needs to be on prevention.

\section{Epidemiology}

Gastric adenocarcinomas can be classified into two major types: intestinal type and diffuse type. The intestinal type of gastric cancer is associated with Helicobacter pylori infection with gastric intestinal metaplasia and atrophy, whereas the diffuse type of gastric cancer originates from pangastritis without atrophy. According to the different anatomic sites, gastric adenocarcinomas are divided into cardia and non-cardia gastric cancers [13]. Most gastric cancers are non-cardia cancers. However, the incidence of cardia gastric cancers has been increasing since the 1970s [14]. Gastric cancer is a genetically heterogeneous tumor with multifactorial etiologies, associated with many environmental and genetic risk factors. Among these, inherited genetic factors, $\mathrm{H}$. pylori infection, dietary factors and lifestyle factors are strongly linked to gastric cancer $[15,16]$.

Dietary factors have an important impact on gastric carcinogenesis, especially in case of the intestinal type of gastric adenocarcinoma. Healthy dietary habits, that is, high intake of fresh fruits and vegetables, a Mediterranean diet, a low-sodium diet, avoiding salt-preserved food, red and high cured meat, sensible alcohol drinking, and maintaining a proper weight are all associated with a decreased risk of gastric cancer $[17,18]$.

According to one study, vegetarians have a $63 \%$ reduced risk of stomach cancer [19]. In a study of Seventh-day Adventists, a religion which encourages vegetarianism along with healthy lifestyles, a 56\% reduction in mortality from stomach cancer was noted and attributed to vegetarian diets [20].

In a study of the Mediterranean diet, a high consumption of legumes, vegetables and low consumption of meat were strongly associated with a lower risk of gastric cancer [21]. A meta study showed that while whole grains reduced the risk of gastric cancer, refined grains increased it [22]. Several studies have reported the protective role of allium vegetables (onion) in gastric cancer [2325].

Higher intake of nutrients found primarily in plant-based foods was associated with a reduced risk of adenocarcinomas of the gastric cardia, whereas higher intake of nutrients found primarily in foods of animal origin was associated with an increased risk [26]. A systematic review and meta-analysis found a two-fold difference in gastric cancer risk among those eating a healthy diet with high fruit and vegetable content to those eating a Western diet high in meat, fats and starches [27]. Processed and red meat intake have been associated with increased gastric cancer risk [27]. Analysis of current data substantially confirm the significant increased risk of developing gastric cancer due to high intake of processed meat and saturated fat $[23,28]$. A prospective investigation into a cancer and nutrition study reported a significant increase of non-cardia cancer risk associated with intake of total meat, red meat, and processed meat [24].

The impact of meat consumption may be partially mediated by the food preservative nitrites used in processed meats $[27,29]$. Dietary nitrite was associated with $65 \%$ increased risk of noncardia gastric cancer [26]. In contrast, plant sources of nitrates are not associated with increased gastric cancer risk [29].

Results from several studies suggested that a diet rich in vitamin $\mathrm{C}$ was protective, whereas a diet high in salt might increase the risk of stomach [30-33] Sources of vitamin C include fresh foods, such as green and yellow vegetables, fruit and other fresh foods, while salt ingestion is from processed, pickled, preserved, salted foods, and also seasoning [34].

Cigarette smoking is also a modifiable risk factor for gastric cancer [35]. However, plant foods may provide some protection for those who are unable to give up cigarettes. A case-control study found that there was an inverse relationship between the consumption of fruits and gastric cancer in male smokers [36].

\section{Pathophysiology}

There is consistent evidence that Helicobacter pylori $(\mathrm{H}$. pylori) infection of the stomach is strongly associated with both the initiation and promotion of carcinoma of the gastric body and antrum and of gastric lymphoma [37-39]. The exact modes and routes of transmission of Helicobacter pylori (H. pylori) infection remain unproven. Studies showed that $H$. pylori bacteria can spread directly from one person to the other, or indirectly from an infected person to the environment. Presently, interpersonal pathways are more probable than environmental exposure routes. Person to person transmission can be mainly fecal-oral or oraloral. In the last 30 years, many authors have investigated the main potential sources of $\mathrm{H}$. pylori infections, vectors and risk factors for both fecal-oral and oral-oral routes of transmission, eating of contaminated food, drinking of contaminated water, and exposure to animals. They have tried to isolate H. pylori from feces, saliva, dental plaque. These aspects are the basis for the effective prevention of both $\mathrm{H}$. pylori acquisition and the gastroduodenal pathology associated with it [40].

It is believed that dietary factors may contribute to the $\mathrm{H}$. pylori infection [41] by providing noxious agents that contribute to $H$. pylori pathogenicity. Production of nitrosylating species plays a fundamental role in this regard. A study showed there was positive association between consumption of sausages and hamburgers with $\mathrm{H}$. pylori infection [42], whereas there was a significant inverse relationship between onion consumption and H. pylori infection [42]. Adequate nutritional status, especially high consumption of fruits, vegetables, and vitamin $\mathrm{C}$, appears to protect against the pathological consequences of $\mathrm{H}$. pylori infection [43]. One study showed a trend for lower incidence of $\mathrm{H}$ pylori among vegetarians [44]. 


\section{Cancer Therapy \& Oncology International Journal}

An inverse association was reported between consumption of unsaturated fat and $\mathrm{H}$. pylori with a significant dose dependency [45]. Ito et al. [46] in their Japanese study indicated that polyunsaturated fatty acids intake decreases the prevalence of atrophic gastritis. Diets high in polyunsaturated fatty acids may protect against duodenal ulcer, possibly through inhibiting the growth of H. pylori [47]. In their prospective trial, Castro et al. demonstrated the bacteriostatic activity of olive oil [48].

Knoops et al. [49,50] stressed the role of vitamin $\mathrm{C}$ as a chemopreventive factor in $\mathrm{H}$. pylori gastric disorders. Vitamin $\mathrm{C}$ is highly concentrated in stomach mucosa and gastric juice and probably lowers the risk of gastric cancer and influences the course of $\mathrm{H}$. pylori infection through several mechanisms $[51,52]$. It has a positive impact on the stimulation and activity of granulocytes, macrophages, and lymphocytes and the production of immunoglobulin. The direct inhibitory impact of this vitamin on the growth of $\mathrm{H}$. pylori is now being examined.

Jarosz et al. [41] showed that a four-week treatment of $\mathrm{H}$. pylori infected patients with chronic gastritis with a high dose of vitamin $\mathrm{C}$ caused $\mathrm{H}$. pylori eradication in $30 \%$ of cases. In those patients, a highly significant rise in gastric juice total vitamin $\mathrm{C}$ concentration was demonstrated, which persisted for at least four weeks after treatment. Ruiz et al. [53] found a causal association between $\mathrm{H}$. pylori infection and low ascorbic acid levels in the gastric juice. Their findings supported two hypotheses that explain this phenomenon: increased oxidation and decreased secretion of ascorbic acid.

Many fruits exhibit in vitro bacteriostatic activity against H. pylori. It is believed that the antibacterial activity of fruit extracts results from their content of phenolic derivatives [54]. Highbush blueberry extract exhibits in vitro activity reducing $\mathrm{H}$. pylori adhesion to mucous, erythrocytes, and gastric epithelial cell culture. A study by Chatterjee et al. proved that raspberry, strawberry, blackberry, and bilberry extracts demonstrate potent bacteriostatic activity against clarithromycin-resistant $\mathrm{H}$. pylori strains [55].

Zhang et al. conducted a prospective randomized doubleblinded trial involving 189 adults with H. pylori infection, who were drinking $250 \mathrm{ml}$ of blueberry juice during a 90-day period. In $14.46 \%$ of patients, urea breath test was negative on the 35 th day. This effect was maintained on the 90th day as well [56].

Sulforaphane, the highest concentrations of which (in the form of a precursor called glucoraphanin) are observed in broccolis and their sprouts, is one of the isothiocyanates inhibiting growth of H. pylori. Sulforaphane also exhibits in vitro bactericidal activity against H. pylori (MIC $2 \mu \mathrm{g} / \mathrm{ml}$ ), including clarithromycin-resistant strains [57]. In the study by Yanaka et al. [58] asymptomatic patients with confirmed $\mathrm{H}$. pylori infection were given broccoli sprout intake of $70 \mathrm{~g} /$ day (containing $420 \mu \mathrm{mol}$ of glucoraphanin), resulting in a significant decrease of colonization intensity, which was assessed in urea breath test and $\mathrm{H}$. pylori antigen stool test.
This therapy was well tolerated, and no adverse effects associated with broccoli sprouts intake were reported.

\section{Clinical considerations}

There are challenges to treating gastric cancer. It's often diagnosed at a late stage. The treatment of gastric cancer remains difficult, and the results are relatively discouraging. Pharmacological treatment of $H$. pylori infection is based on at least two antibiotics combined with a double dose of proton-pump inhibitor (PPI). The estimated efficacy of this therapy is $82 \%$ (triple regimen) to $92 \%$ (sequential therapy). New therapeutic regimens, containing fluoroquinolones (levofloxacin and moxifloxacin), exhibit high efficacy ( $85 \%$ and $90 \%$, respectively) and good safety profile, but their use is limited by high costs [59]. The problem of eradication therapy is the abruptly increasing resistance of $\mathrm{H}$. pylori to the most used antibiotics. Moreover, eradication therapy requires multiple-day complex drug administration and is associated with side effects, mainly gastrointestinal (e.g. diarrhea, nausea, and taste disturbances), which can lead to treatment discontinuation. In addition to antibiotic resistance, it is believed that lack of observance to doctor's prescriptions is the main cause of eradication failure [60]. Therefore, prevention, which is always desirable, should be practiced.

A whole foods plant-based diet high in fruits and vegetables, legumes and whole grains, will naturally include high levels of vitamin $\mathrm{C}$, phenolic derivatives and sulforaphanes, which are shown to have bacteriostatic and bactericidal actions against $\mathrm{H}$. Pylori. Avoiding processed and red meat will reduce the exposure to nitrites and lower salt intake. The value of the plant-based diet rises even further when we consider that it lowers the risk of prostate, breast and colorectal cancer [61-63].

Patient compliance on plant-based diets has been good in almost all studies. The degree of compliance has often been very high. For instance, one study obtained a $99 \%$ compliance [64]. In a 22 -week study $94 \%$ of subjects on a vegan diet were compliant [65]. In a somewhat longer study, $84 \%$ of the participants in each group completed all 24 weeks [66]. In studies of patients placed on plant-based diets for coronary artery disease, high compliance has been noted even over several years. For instance, one study of patients placed on a plant-based diet showed $89 \%$ compliance for 3.7 years [67]. Compliance may be enhanced when the rationale for the treatment, and that the treatment is backed by research, is explained to the patient [68]. The doctor should prescribe the treatment by writing it down on a prescription form or other stationery with the physician's name on it. This written prescription is not only valuable to the patient but can also be valuable in enlisting the support of family, friends and social contacts.

The incidence of gastric cancer occurs mainly in older patients [69]. Many of these patients will be at risk for cardiovascular disease, type 2 diabetes and may already have or be at risk for other gastrointestinal pathologies such as gall stone disease, 


\section{Cancer Therapy \& Oncology International Journal}

diverticular disease, ulcerative colitis and Crohn's disease. Fortunately, in addition to reducing the risk of gastric cancer, a plant-based diet can help prevent and treat these other diseases [70-75]. It's important to titrate medications when starting a patient on a plant-based diet as the effect of the diet becomes evident. For instance, a plant-based diet is more effective in reducing glycated hemoglobin than Metformin [71], so a patient may be at risk of hypoglycemia if the medication is not titrated.

\section{Discussion}

Though the incidence of gastric cancer has diminished in the United States, there are still a number of cases and it still remains high in other countries especially in east Asia. Gastric cancer continues to have a very poor prognosis at the most common time of diagnosis. Prevention, always of prime importance, is even more so in the case of gastric cancer. A plant-based diet rich in fruits and vegetables can lower the risk of gastric cancer considerably Smoking cessation would lower the risk even more, but even smokers can lower their risk of gastric cancer with a plant-based diet. While reducing consumption of alcohol and cigarettes are well established, fewer patients are aware of the impact of their dietary choices. It is important for the physician to explain how their food choices impact their risk of stomach cancer. The plantbased diet has no adverse reactions and no contraindications. It can safely be used as an adjunct to pharmacotherapy. It is also very affordable.

\section{References}

1. Cancer fact sheet (2021) World Health Organization. WHO.

2. Cancer stat facts: (2020) Stomach cancer. National Cancer Institute surveillance, epidemiology and end results program. NIH.

3. Cheng X, Lin J, Tu S (2016) Etiology and Prevention of Gastric Cancer Gastrointest Tumors 3(1): 25-36.

4. Hansson L, Nyren O, Hsing A, Bergstrom R, Josefsson S, et al. (1996) The risk of stomach cancer in patients with gastric or duodenal ulcer disease. N Engl J Med 335(4): 242-249.

5. Kuipers E, Thijs J, Festen H (1995) The prevalence of Helicobacter pylori in peptic ulcer disease. Aliment Pharmacol Ther 9 Suppl 2: 59-69.

6. Bustamante M, Devesa F, Borghol A, Ortuno J, Ferrando M (2002) Accuracy of the initial endoscopic diagnosis in the discrimination of gastric ulcers: is endoscopic follow-up study always needed? J Clin Gastroenterol 35(1): 25-28.

7. Lv SX, Gan JH, Ma XG, Wang CC, Chen HM (2012) Biopsy from the base and edge of gastric ulcer healing or complete healing may lead to detection of gastric cancer earlier: an 8 years endoscopic follow-up study. Hepatogatroenterology 59(115): 947-950.

8. Amorena Muro E, Borda Celaya F, Martinez-Penuela Virseda J, Borobio Aguilar E, et al. (2009) Analysis of the clinical benefits and cost-effectiveness of performing a systematic second-look gastroscopy in benign gastric ulcer. Gastroenterol Hepatol 32(1): 2-8.

9. Sogaard K, Farkas D, Pedersen L, Lund J, Thomsen R, et al. (2016) Longterm risk of gastrointestinal cancers in persons with gastric or duodenal ulcers. Cancer Med 5(6): 1341-1351.

10. Kumar V, Abbas A, Aster J (2017) Robbins Basic Pathology. $10^{\text {th }}$ ed, Philadelphia, Elsevier.
11. Gunderson LL, Sosin H (1982) Adenocarcinoma of the stomach: areas of failure in a re-operation series (second or symptomatic look) clinicopathologic correlation and implications for adjuvant therapy. Int J Radiat Oncol Biol Phys 8(1): 1-11.

12. Orditura M, Galizia G, Sforza V, Gambardella V, Fabozzi A, et al. (2014) Treatment of gastric cancer. World J Gastroenterol 20(7): 1635-1649.

13. Lauren P (1965) The two histological main types of gastric carcinoma: diffuse and so-called intestinal-type carcinoma. An attempt at a histo-clinical classification. Acta Pathol Microbiol Scand 64: 31-49.

14. Crew K, Neugut A (2006) Epidemiology of gastric cancer. World J Gastroenterol 12(3): 354-362.

15. Karimi P, Islami F, Anandasabapathy S, Freedman N, Kamangar F (2014) Gastric cancer: descriptive epidemiology, risk factors, screening, and prevention. Cancer Epidemiol Biomarkers Prev 23(5): 700-713.

16. Eid R, Moss S (2002) Helicobacter pylori infection and the development of gastric cancer. N Engl J Med 346(1): 65-67.

17. Buckland G, Travier N, Huerta JM, Bueno-de-Mesquita H, Siersema P, et al. (2015) Healthy lifestyle index and risk of gastric adenocarcinoma in the EPIC cohort study. Int J Cancer 137(3): 598-606.

18. Lin S, Li Y, Leung K, Huang C, Wang X (2014) Salt processed food and gastric cancer in a Chinese population. Asian Pac J Cancer Prev 15(13): 5293-5298.

19. Key T, Appleby P, Crowe F, Bradbury K, Schmidt J, et al. (2014) Cancer in British vegetarians: updated analyses of 4998 incident cancers in a cohort of 32,491 meat eaters, 8612 fish eaters, 18,298 vegetarians, and 2246 vegans. Am J Clin Nutr 100(Suppl 1): 378S-385S.

20. Phillips RL (1975) Role of Life-style and Dietary Habits in Risk of Cancer among Seventh-Day Adventists. Cancer Res 35(11): 3513-3522.

21. Stojanovic J, Giraldi L, Arzani D, Pastorino R, Biondi A, et al. (2017) Adherence to Mediterranean diet and risk of gastric cancer: results of a case-control study in Italy. Eur J Cancer Prev 26(6): 491-496.

22. Xu Y, Yang J, Du L, Li K, Zhou Y (2018) Association of whole grain, refined grain, and cereal consumption with gastric cancer risk: A meta-analysis of observational studies. Food Sci Nutr 7(1): 256-265.

23. Jansen MCJF, Bueno-de-Mesquita HB, Rasanen L, Fidanza F, Menotti A, et al. (1999) Consumption of plant foods and stomach cancer mortality in the seven countries study. Is grain consumption a risk factor? Nutrition and Cancer 34(1): 49-55.

24. Gonzalez CA, Jakszyn P, Pera G, Agudo A, Bingham S, et al. (2006) Meat intake and risk of stomach and esophageal adenocarcinoma within the European Prospective Investigation into Cancer and Nutrition (EPIC). Nat Cancer Inst 98(5): 345-354.

25. Munoz N, Plummer M, Vivas J, Moreno V, De Sanjose S, et al. (2001) A case-control study of gastric cancer in Venezuela. Int J Cancer 93(3): 417-423.

26. Mayne ST, Risch HA, Dubrow R, Chow WH, Gammon MD, et al. (2001) Nutrient intake and risk of subtypes of esophageal and gastric cancer. Cancer Epidemiol Biomarkers Prev 10(10): 1055-1062.

27. Van Blarigan E, Meyerhardt J (2015) Role of physical activity and diet after colorectal cancer diagnosis. J Clin Oncol 33(16): 1825-1834.

28. Kneller RW, McLaughlin JK, Bjelke E, Schuman L, Blot W, et al. (1991) A cohort study of stomach cancer in a high-risk American population. Cancer 68(3): 672-678.

29. Bertuccio P, Rosato V, Andreano A, Ferraroni M, Decarli A, et al. (2013) Dietary patterns and gastric cancer risk: a systematic review and meta-analysis. Ann Oncol 24(6): 1450-1458.

30. Mirvish S, Wallcave L, Eagen M, Shubik P (1972) Ascorbate-nitrite reaction: possible means of blocking the formation of carcinogenic N-nitroso compounds. Science 177(4043): 65-68. 


\section{Cancer Therapy \& Oncology International Journal}

31. Raineri R, Weisburger J (1975) Reduction of gastric carcinogens with ascorbic acid. Ann NY Acad Sci. 258: 181-189.

32. Joossens J, Hill M, Elliott P, Stamler R, Lesaffre E, et al. (1996) Dietary salt, nitrate and stomach cancer mortality in 24 countries. European Cancer Prevention (ECP) and the INTERSALT Cooperative Research Group. Int J Epidemiol 25(3): 494-504.

33. Zhang Z, Abdullahi M, Farthing M (2002) Effect of physiological concentrations of vitamin $\mathrm{C}$ on gastric cancer cells and Helicobacter pylori. Gut 50: 165-169.

34. Kagawa A (1991) Standard Tables of Food Composition in Japan. Daigaku Shuppanbu: Joshi Eiyou. CiNii.

35. Gonzalez C, Agudo A (2012) Carcinogenesis, prevention and early detection of gastric cancer: where we are and where we should go. Int J Cancer 130: 745-753.

36. Epplein M, Shu XO, Xiang YB, Chow WH, Yang G, et al. (2010) Fruit and vegetable consumption and risk of distal gastric cancer in the Shanghai Women's and Men's Health studies. Am J Epidemiol 172: 397-406.

37. Parsonnet J, Hansen S, Rodriguez L, Gelb A, Warnke R, et al. (1994) Helicobacter pylori infection and gastric lymphoma. N Engl J Med 330(18): 1267-1271.

38. Ando T, Goto Y, Maeda O, Watanabe O, Ishiguro K, et al. (2006) Causal role of Helicobacter pylori infection in gastric cancer. World J Gastroenterol. 12(2): 181-186.

39. Aromaa A, Kosunen TU, Knekt P, Maatela J, Teppo L, et al. (1996) Circulating anti-Helicobacter pylori immunoglobulin A antibodies and low serum pepsinogen I level are associated with increased risk of gastric cancer. Am J Epidemiol 144 (2): 142-149.

40. Mladenova I, Durazzo M (2018) Transmission of Helicobacter pylori. Minerva Gastroenterol Dietol. 64(3): 251-254.

41. Jarosz M, Rychlik E, Siuba H, Respondek W, Ryzko-Skiba M, et al. (2009) Dietary and socio-economic factors in relation to Helicobacter pylori re-infection. World J Gastroenterol 15(9): 1119-1125.

42. Mard S, Khadem Haghighian H, Sebghatulahi V, Ahmadi B (2014) Dietary Factors in Relation to Helicobacter pylori Infection. Gastroenterol Res Pract 2014: 826910.

43. Izzotti A, Durando P, Ansaldi F, Gianiorio F, Pulliero A (2009) Interaction between Helicobacter pylori, diet, and genetic polymorphisms as related to non-cancer diseases. Mutation Research: Fundamental and Molecular Mechanisms of Mutagenesis 667(1-2): 142-157.

44. Rastogi M, Rastogi D, Singh S, Agarwal A, Priyadarshi BP, et al. (2015) Prevalence of Helicobacter pylori in asymptomatic adult patients in a tertiary care hospital: A cross sectional study. Biomedical Research Physiology 26(1)

45. Lopez-Carrillo L, Lopez-Cervantes M, Ward MH, Bravo-Alvarado J Ramirez-Espitia A (1999) Nutrient intake and gastric cancer in Mexico. Int J Cancer 83(5): 601-605.

46. Ito Y, Suzuki K, Ichino N, Imai H, Sakaguchi H, et al. (2000) The risk of Helicobacter pylori infection and atrophic gastritis from food and drink intake: a cross-sectional study in Hokkaido, Japan. Asian Pac J Cancer Prev 1(2): 147-156.

47. Thompson L, Cockayne A, Spiller R (1994) Inhibitory effect of polyunsaturated fatty acids on the growth of Helicobacter pylori: a possible explanation of the effect of diet on peptic ulceration. Gut 35(11): 15571561.

48. Castro M, Romero C, de Castro A, Vargas J, Medina E, et al. (2012) Assessment of Helicobacter pylori eradication by virgin olive oil. Helicobacter 17(4): 305-311.
49. Knoops K, De Groot L, Kromhout D, Perrin A, Moreiras-Varela O, et al. (2004) Mediterranean diet, lifestyle factors, and 10-year mortality in elderly European men and women: the HALE project. J Am Med Ass 292(12): 1433-1439.

50. Riboli E, Slimani N, Kaaks R (1996) Identifiability of food components for cancer chemoprevention. IARC Sci Publ (139): 23-31.

51.Jarosz M, Dzieniszewski J, Dabrowska-Ufniarz E, Wartanowicz M Ziemlanski S, et al. (1998) Effects of high dose vitamin C treatment on Helicobacter pylori infection and total vitamin $C$ concentration in gastric juice. Eur J Cancer Prev 7(6): 449-454.

52. Shi LQ, Zheng RL (2006) DNA damage and oxidative stress induced by Helicobacter pylori in gastric epithelial cells: protection by vitamin C and sodium selenite. Pharmazie 61(7): 631-637.

53. Ruiz B, Rood, J, Fontham E, Malcom G, Hunter F, et al. (1994) Vitamin C concentration in gastric juice before and after anti-Helicobacter pylori treatment. Am J Gastroenterol 89(4): 533-539.

54. Nohynek LJ, Alakomi HL, Kahkonen MP, Heinonen M, Helander I, et al (2006) Berry phenolics: antimicrobial properties and mechanisms of action against severe human pathogens. Nutr Cancer 54(1): 18-32.

55. Chatterjee A, Yasmin T, Bagchi D, Stohs SJ (2004) Inhibition of Helicobacter pylori in vitro by various berry extracts, with enhanced susceptibility to clarithromycin. Mol Cell Biochem 265(1-2): 19-26.

56. Zhang L, Ma J, Pan K, Go V, Chen J, et al. (2005) Efficacy of cranberry juice on Helicobacter pylori infection: a double-blind, randomized placebo-controlled trial. Helicobacter 10(2): 139-145.

57. Fahey JW, Haristoy X, Dolan PM, Kensler T, Scholtus I, et al. (2002) Sulforaphane inhibits extracellular, intracellular, and antibiotic-resistant strains of Helicobacter pylori and prevents benzo[a]pyrene-induced stomach tumors. Proc Natl Acad Sci USA 99(11): 7610-7615.

58. Yanaka A, Fahey J, Fukumoto A, Nakayama M, Inoue S, et al. (2009) Dietary sulforaphane-rich broccoli sprouts reduce colonization and attenuate gastritis in Helicobacter pylori-infected mice and humans. Cancer Prev Res (Phila) 2(4): 353-360.

59. Li B, Threapleton D, Wang J, Xu J, Yuan J, et al. (2015) Comparative effectiveness and tolerance of treatments for Helicobacter pylori: systematic review and network meta-analysis. BMJ 351: h4052.

60. Holubiuk L, Imiela J (2016) Diet and Helicobacter pylori infection. Prz Gastroenterol 11(3): 150-154.

61. Rose S, Strombom A (2018) A plant-based diet prevents and treats prostate cancer. Canc Therapy \& Oncol Int J 11(3): 555813.

62. Rose S, Strombom A (2020) Breast Cancer Prevention with a PlantBased Diet. Canc Therapy \& Oncol Int J 17(1): 555955.

63. Rose S, Strombom A (2019) Colorectal Cancer Prevention with a PlantBased Diet. Canc Therapy \& Oncol Int J 15(2): 555906.

64. Bloomer R, Kabir M, Canale R, Trepanowski J, Marshall K, et al. (2010) Effect of a 21-day Daniel Fast on metabolic and cardiovascular disease risk factors in men and women. Lipids Health Dis 9: 94.

65. Barnard N, Cohen J, Jenkins D, Turner-McGrievy G, Gloede L, et al (2006) A low-fat vegan diet improves glycemic control and cardiovascular risk factors in a randomized clinical trial in individuals with type 2 diabetes. Diabetes Care 29(8): 1777-1783.

66. Kahleova H, Matoulek M, Bratova M, Malinska H, Kazdova L, et al (2013) Vegetarian diet-induced increase in linoleic acid in serum phospholipids is associated with improved insulin sensitivity in subjects with type 2 diabetes. Nutr Diabetes 3: e75.

67. Esselstyn CJ, Gendy G, Doyle J, Golubic M, Roizen M. (2014) A way to reverse CAD? J Fam Pract 63(7): 356-364b. 


\section{Cancer Therapy \& Oncology International Journal}

68. Drozek D, Diehl H, Nakazawa M, Kostohryz T, Morton D, et al. (2014) Short-term effectiveness of a lifestyle intervention program for reducing selected chronic disease risk factors in individuals living in rural appalachia: a pilot cohort study. Advances in Preventive Medicine 2014: 798184

69. Christie J, Shepherd NA, Codling BW, Valori RM (1997) Gastric cancer below the age of 55: implications for screening patients with uncomplicated dyspepsia. Gut BMJ 41(4): 513-517.

70. Rose S, Strombom A. (2018) A comprehensive review of the prevention and treatment of heart disease with a plant-based diet. J Cardiol \& Cardiovas Ther 12(5): 555847.

71. Strombom A, Rose S (2017) The prevention and treatment of Type II Diabetes Mellitus with a plant-based diet. Endocrin Metab Int J 5(5): 00138 .
72. Rose S, Strombom A (2020) Gall stones - prevention with a plantbased diet. Adv Res Gastroentero Hepatol 14(3): 555891.

73. Rose S, Strombom A (2019) Diverticular Disease risk reduced with a plant-based diet. Adv Res Gastroenterol Hepatol 14(2): 555884

74. Rose S, Strombom A. (2020) Ulcerative Colitis - prevention and treatment with a plant-based diet. Adv Res Gastroentero Hepatol 15(2): 555908.

75. Rose S, Strombom A (2018) Crohn's disease prevention and treatment with a plant-based diet. Adv Res Gastroentero Hepatol 9(1).

Your next submission with Juniper Publishers will reach you the below assets

- Quality Editorial service

- Swift Peer Review

- Reprints availability

- E-prints Service

- Manuscript Podcast for convenient understanding

- Global attainment for your research

- Manuscript accessibility in different formats

( Pdf, E-pub, Full Text, Audio)

- Unceasing customer service

Track the below URL for one-step submission https://juniperpublishers.com/online-submission.php 